\title{
Lapsikylä Orion: Koti ja ympäristö
}

Mikä on lapsikylä Orion? Orion on pedagogien, pyskologien ja vanhempien yhteisö, joka toimii lastenoikeuksien parissa, erityisesti lastensuojelun kysymyksissä. Noin 60 kilometrin päässä Moskovasta sijaitseva yhteisö on perustettu vuonna 2004. Lapsikylä auttaa niitä lapsia, jotka ovat vaarassa menettää tai ovat menettäneet vanhempiensa huolenpidon tarjoamalla näille väliaikaisen tai pysyvämmän kodin sijaisperheessä. Orionissa kohtaavat lasten kasvatuksen keskeisimmät instituutiot: perhe ja koulu. Tällä hetkellä siellä asuu kahdeksan sijaisperhettä.

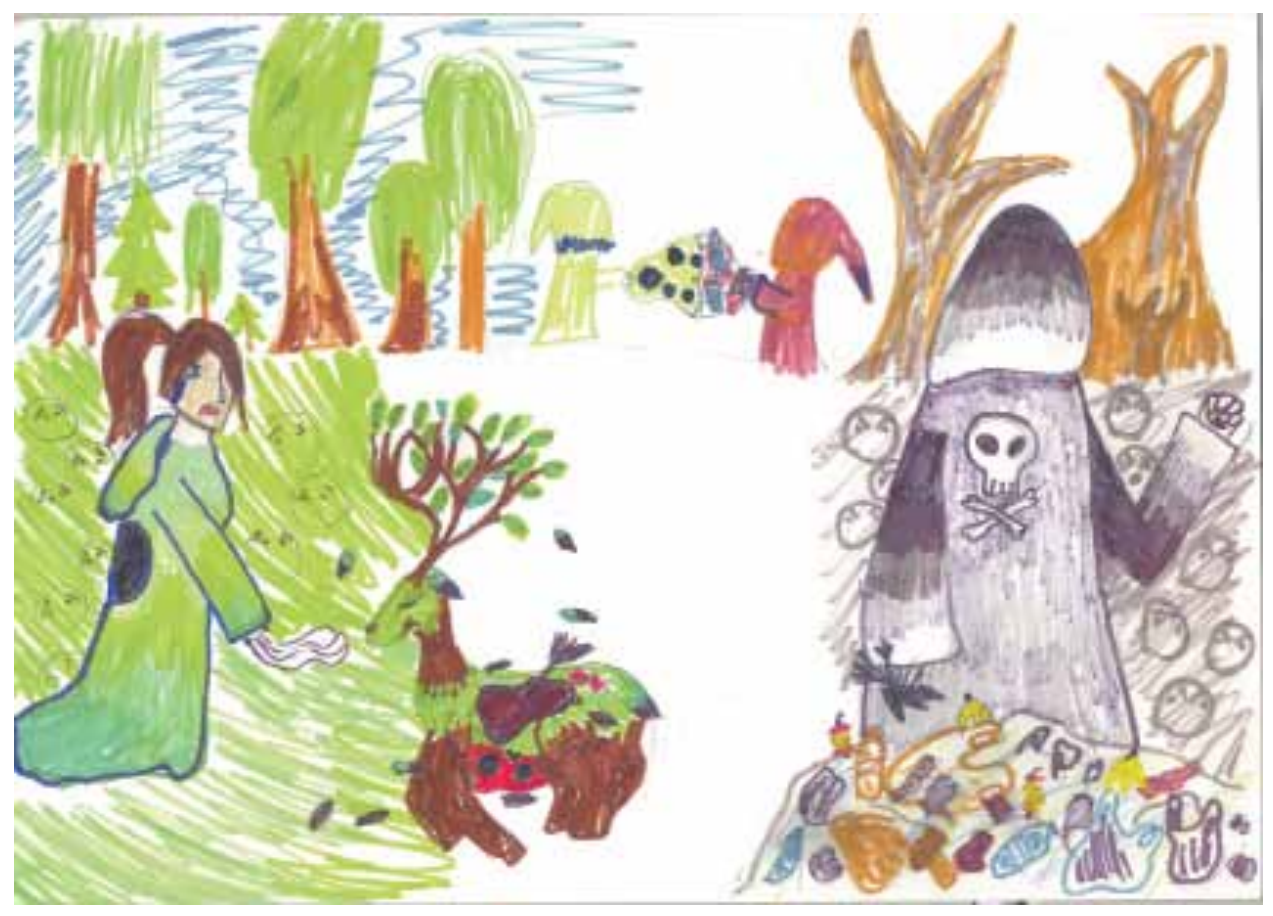

Kuva 1: Alisa Jezerskaja, 12 vuotta. 
Perheissä on yhteensä 34 lasta, joista 20 ovat sijaishuollossa ja loput sijaisvanhempina toimivien perheiden biologisia lapsia. Lisäksi Orionissa asuu neljä vapaaehtoisperhettä, jotka auttavat opetus- ja kasvatustyössä. Elämä kylässä on pedagogisesti orientoitunutta ja siellä järjestetäänkin lapsille monenlaista opetus- ja harrastustoimintaa useiden vanhempien ollessa ammatiltaan pedagogeja. Kylässä asuvat perheet jakavat yhteisen arvomaailman ja kasvatuksellisen näkemyksen. Yhteisön vanhemmat ovat keskenään niin ystäviä kuin kollegoita, mikä mahdollistaa ammatillisen psykologis-pedagogisen yhteistyön ja tuen sekä sen, että kriisitilanteiden sijaan perheiden keskinäinen tuki on jokapäiväistä.

Yhteisöä johtaa Maria Kuzmina, joka on itse kasvanut vastaavassa Kitežin lapsikylässä. Marian perheessä on kahdeksan lasta, joista sijaislapsia on kuusi. Lapsikylän elämää voi seurata heidän Facebook-sivuiltaan: https:/www.facebook.com/DetskiyPoselokOrion/.

Orionin ohella Venäjällä toimii useita erilaisilla periaatteilla toimivia lapsi- tai sijaisperhekyliä, myös maailmanlaajuisesti toimiva kansainvälinen SOS-lapsikyläjärjestö. Useimmiten kylät Venäjällä ovat järjestöpohjaisia ja toimivat pääosin yksityisellä rahoituksella.

Lapsikylä Orionissa asuvia lapsia pyydettiin piirtämään tätä Idäntutkimuksen teemanumeroa varten. Lapset saivat itse valita haluamansa teeman ja teemaksi valittiin "Kotini ja ympäristö”. Kaikki lapset ja heidän vanhempansa ovat antaneet suostumuksensa niin piirrosten kuin piirtäjien nimien julkaisuun.

\section{Maksim Anikijev \& Meri Kulmala}

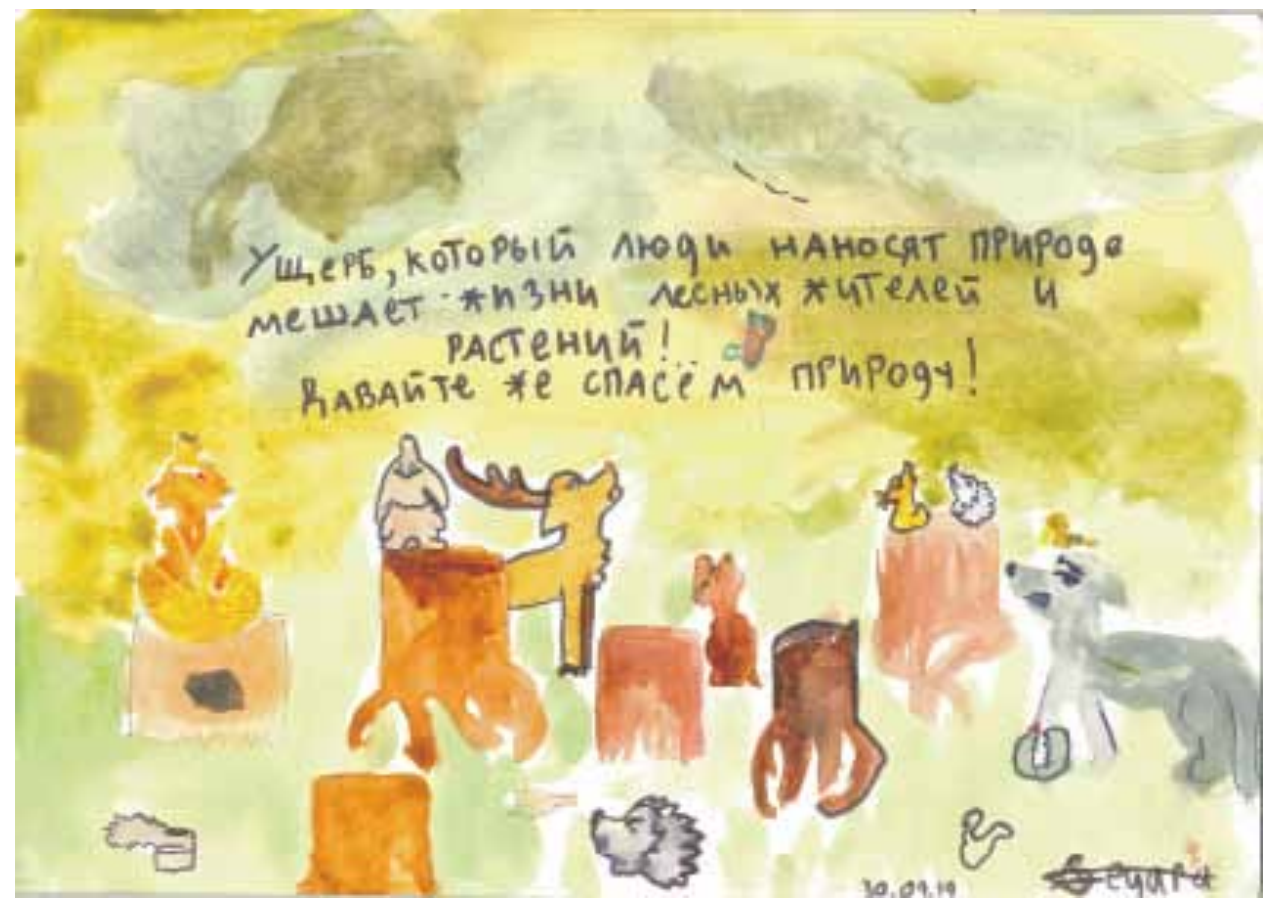

Kuva 2: Sejara Žalilova, 12 vuotta. 


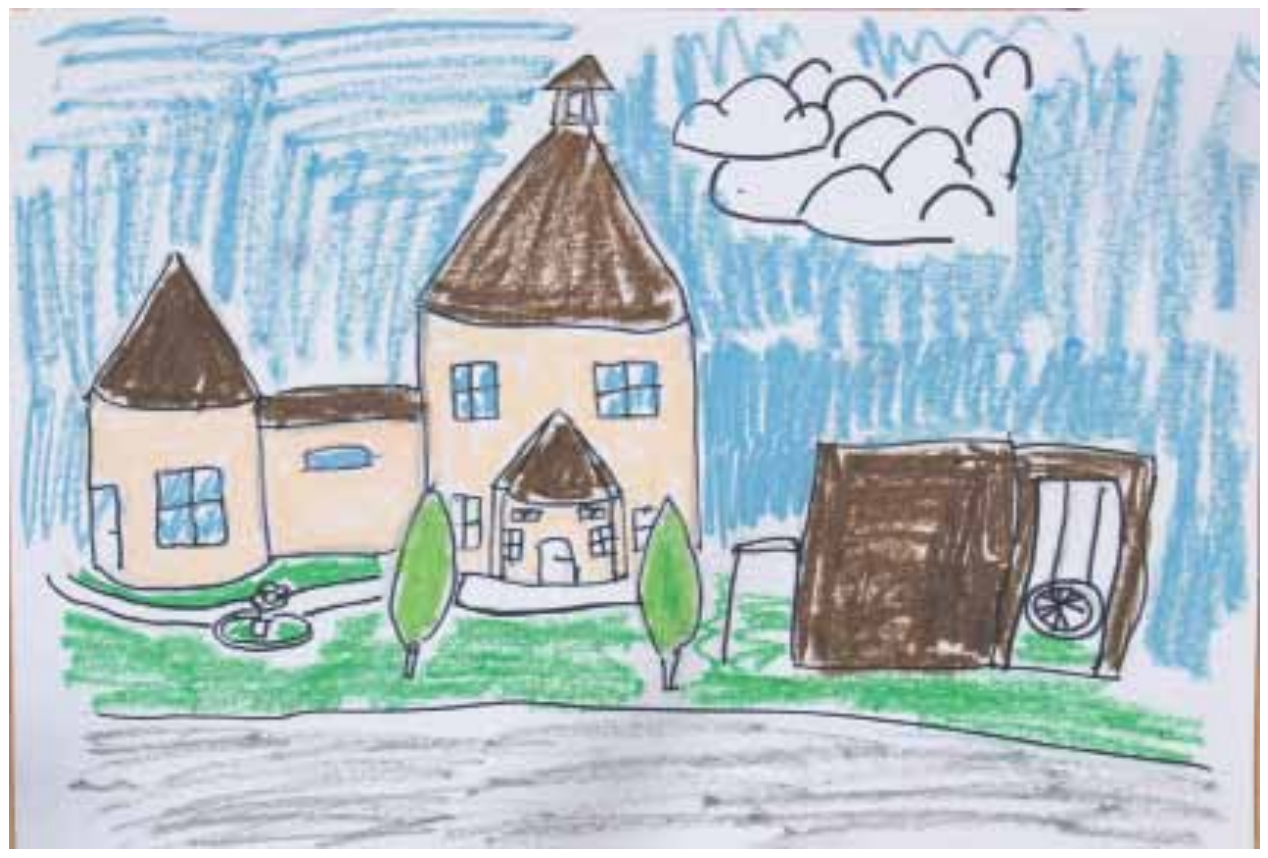

Kuva 3: Maksim Pavlov, 12 vuotta.

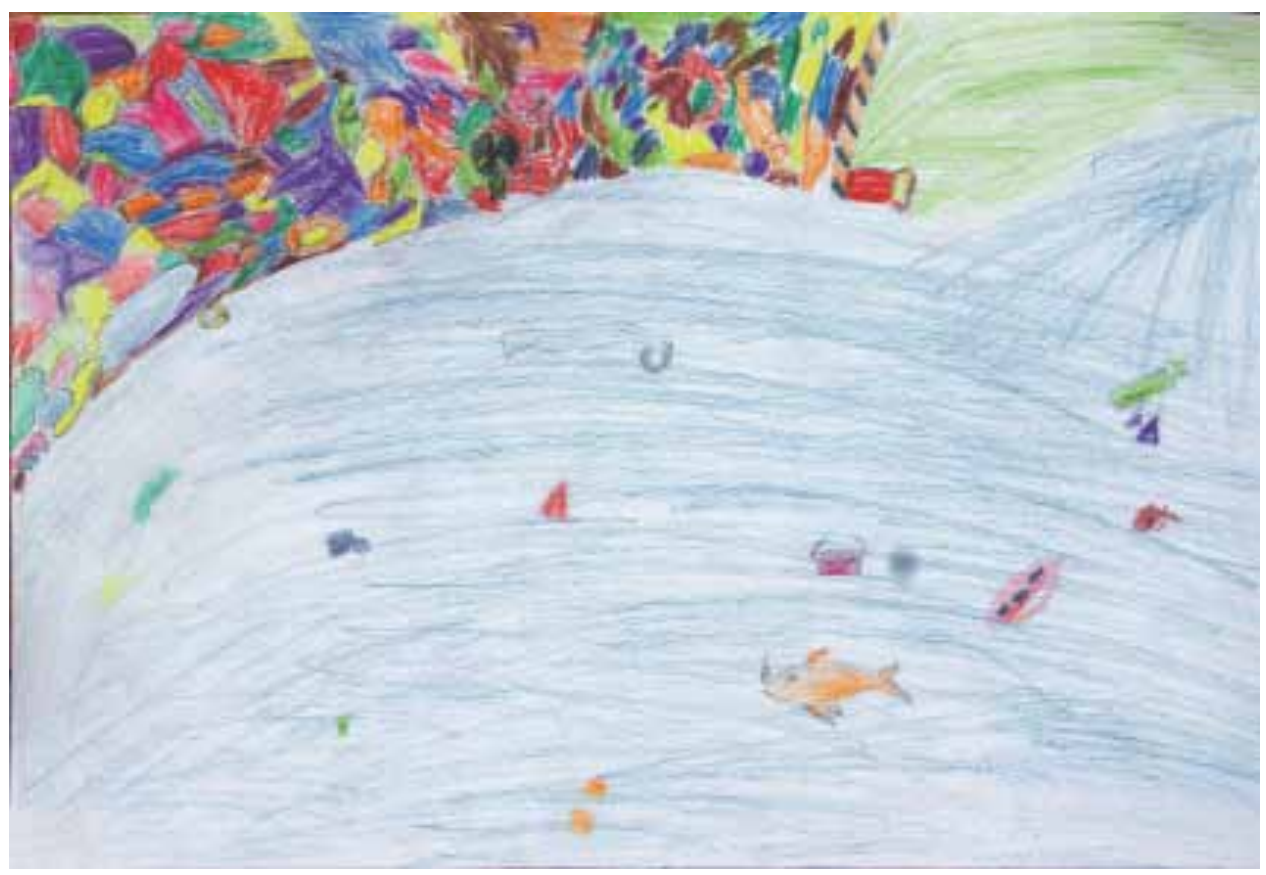

Kuva 4: Gleb Malevski, 12 vuotta. 


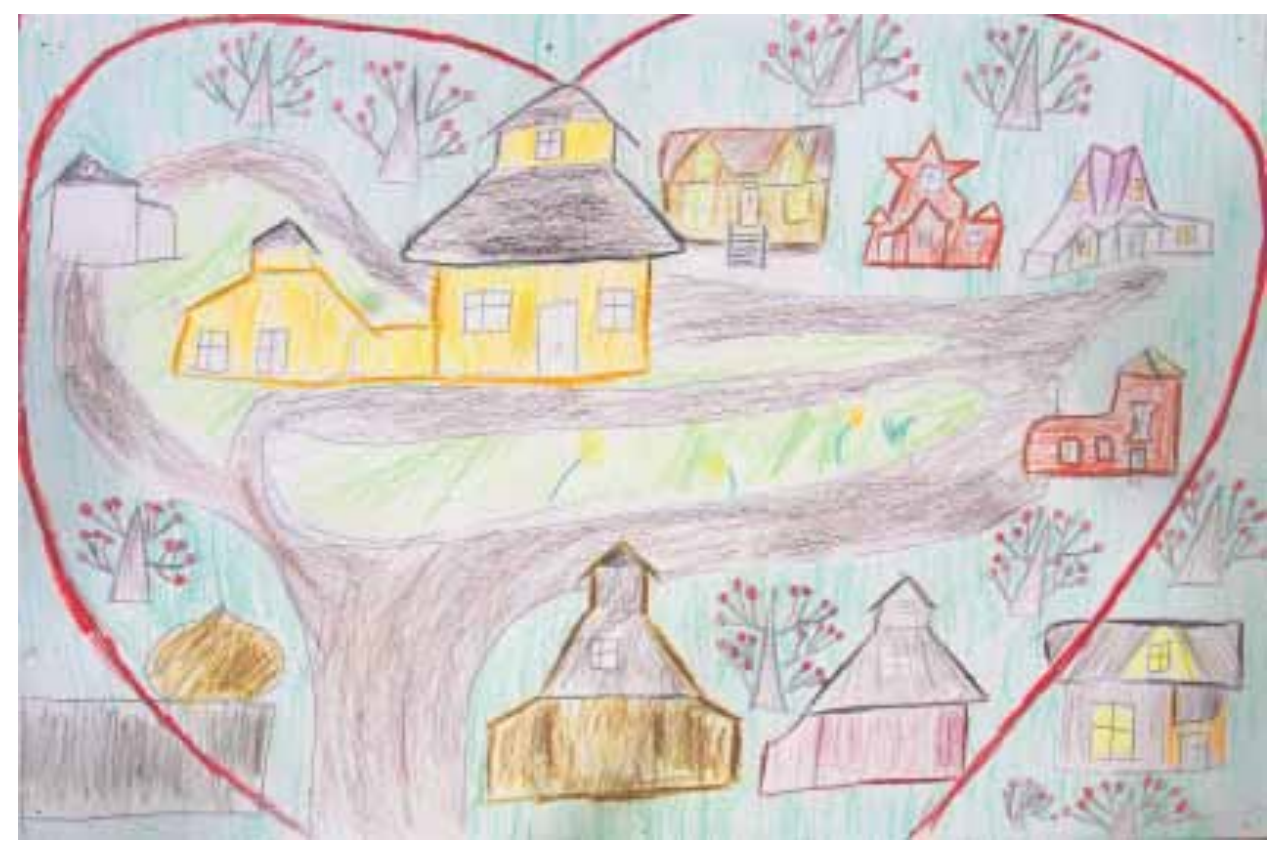

Kuva 5: Matvei Malinin, 12 vuotta.

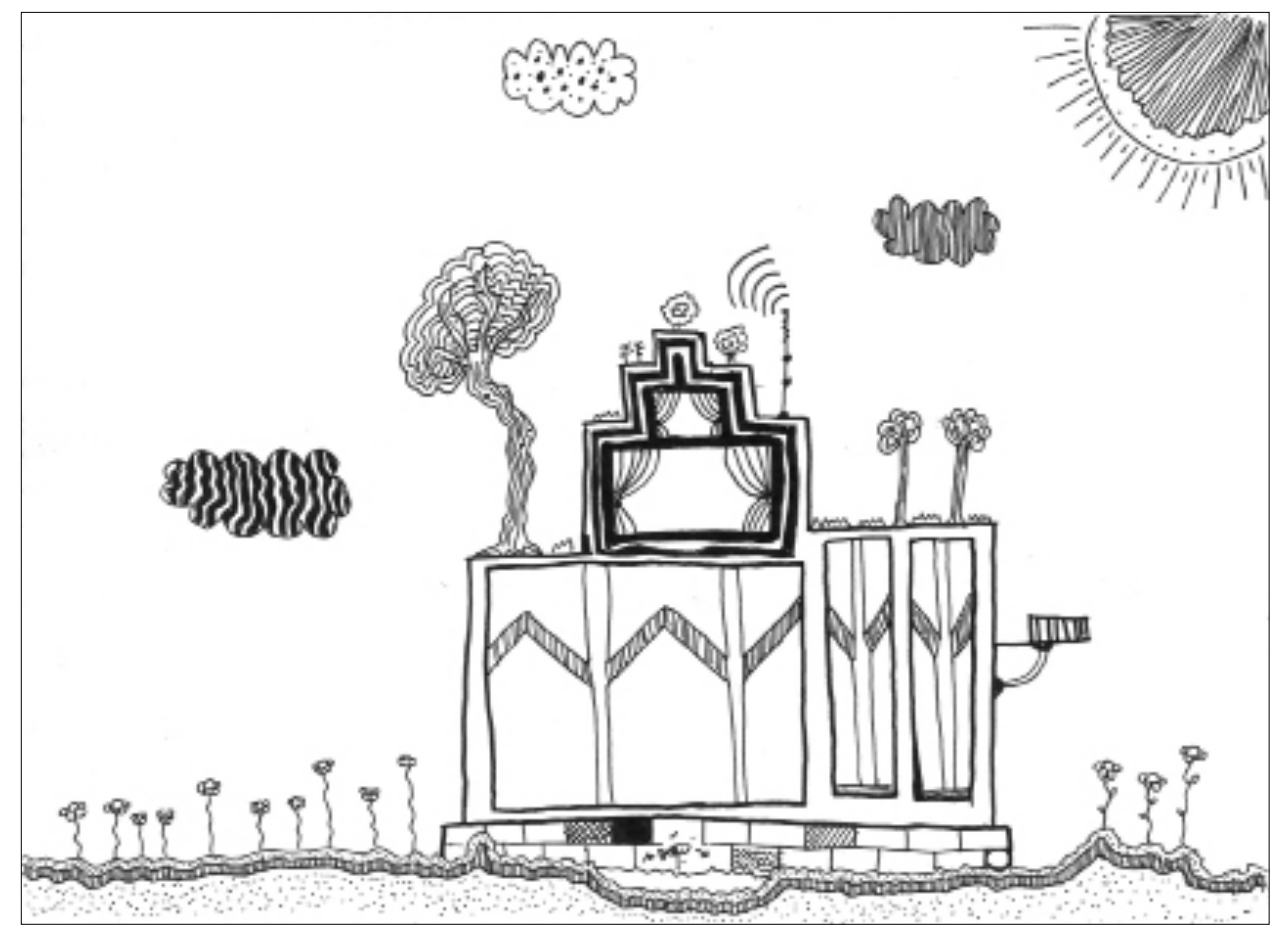

Kuva 6: Matvei Malinin, 12 vuotta. 


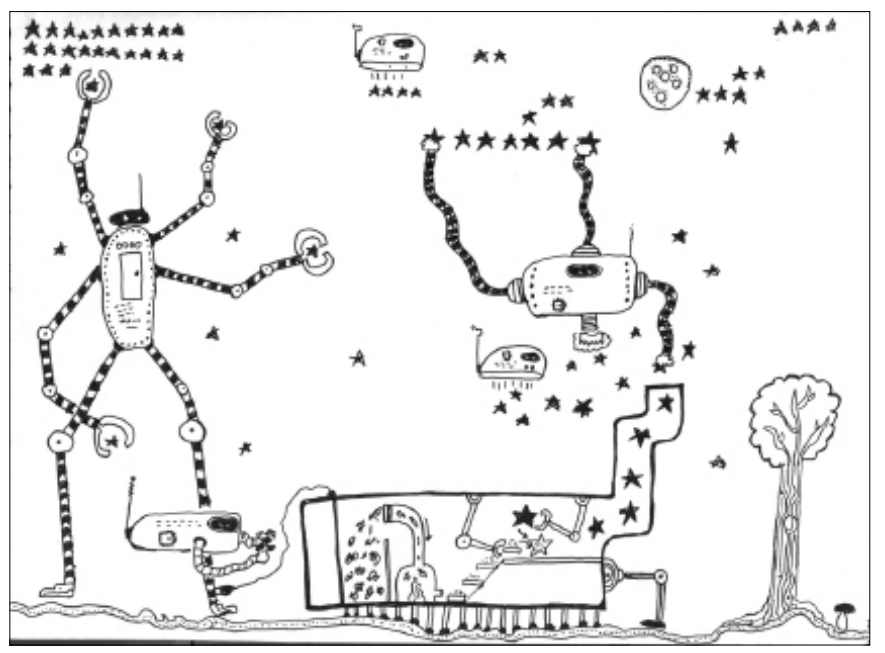

Kuva 7: Matvei Malinin, 12 vuotta.
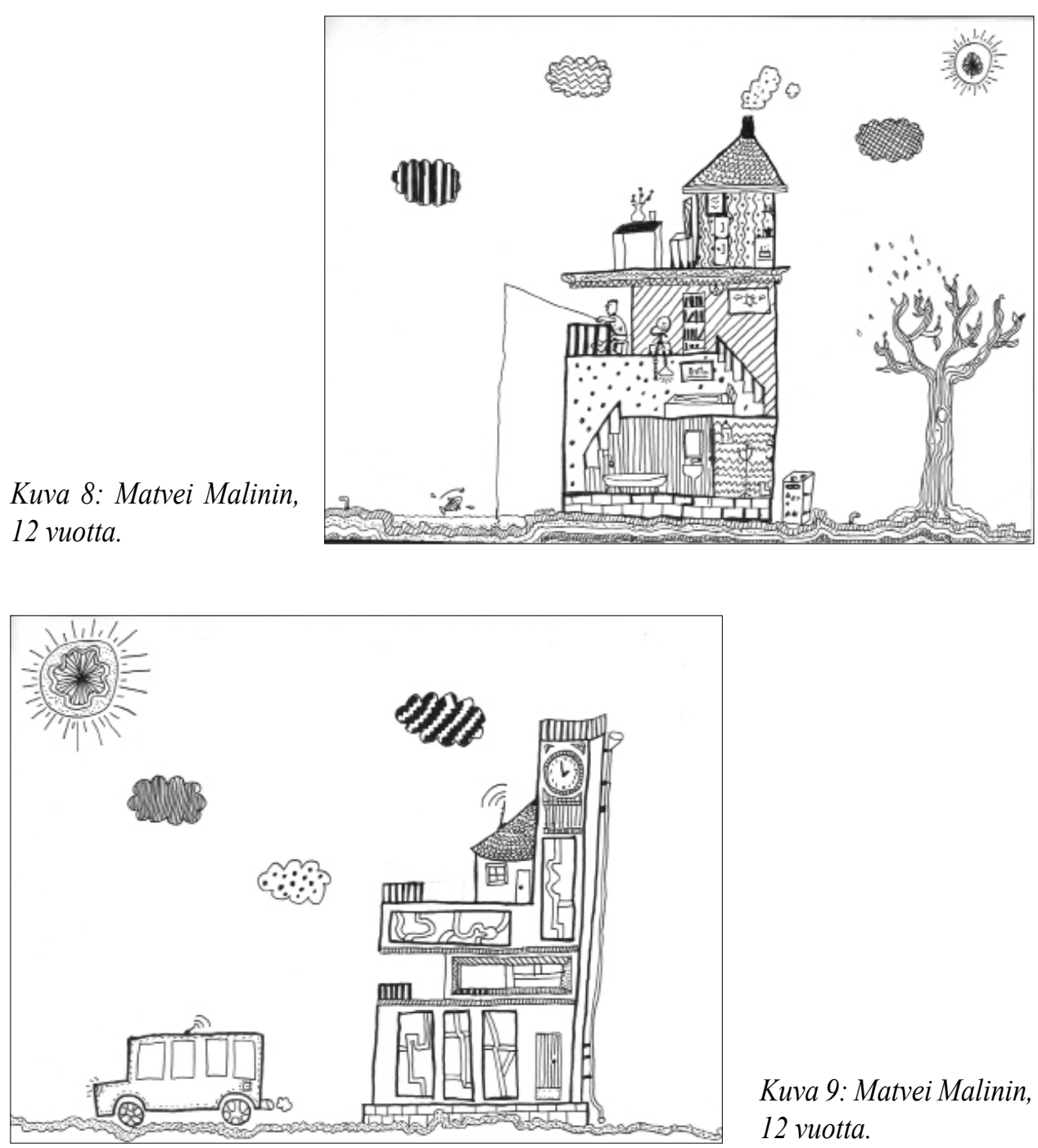

Kuva 9: Matvei Malinin, 12 vuotta. 


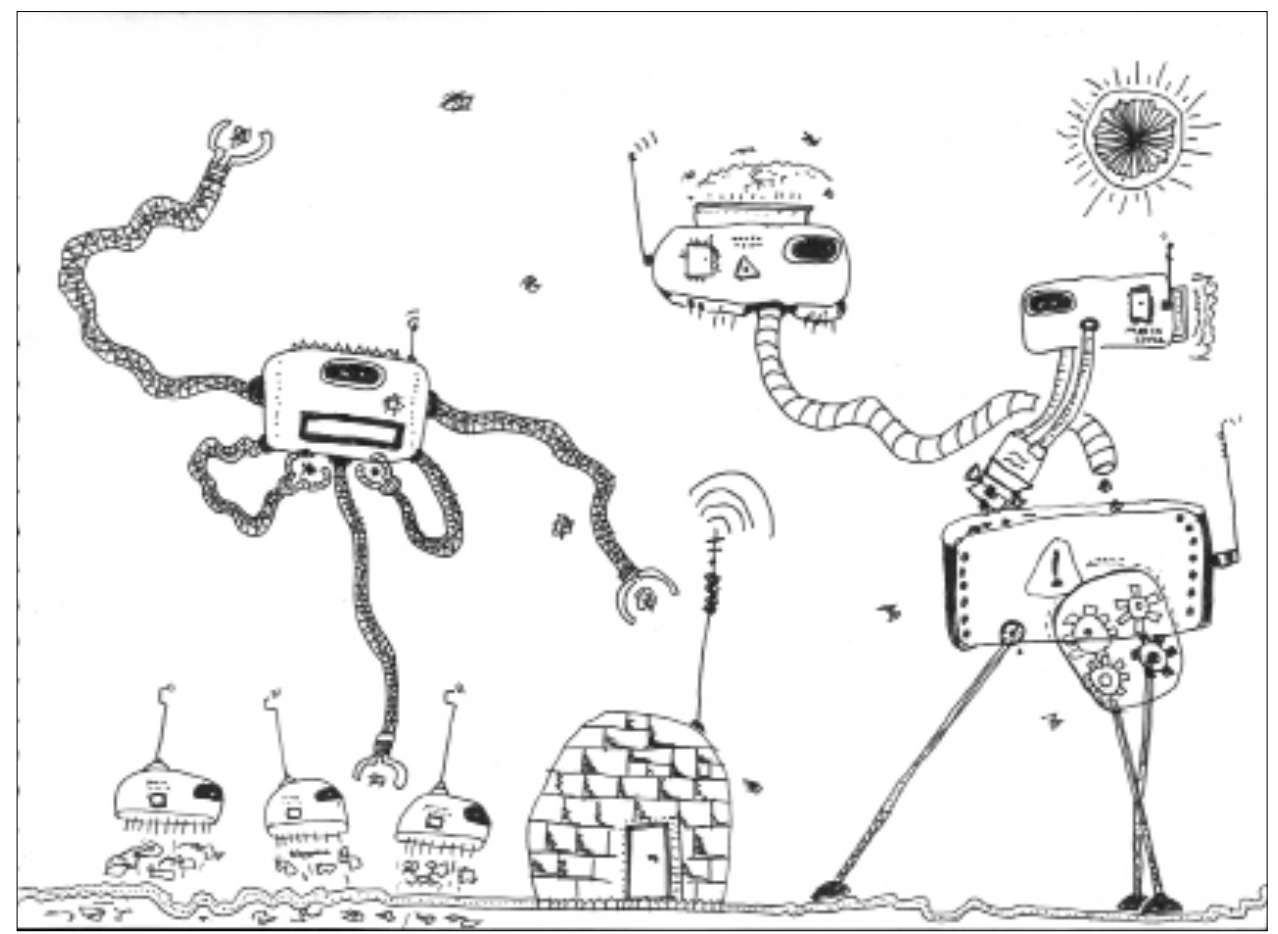

Kuva 10: Matvei Malinin, 12 vuotta.

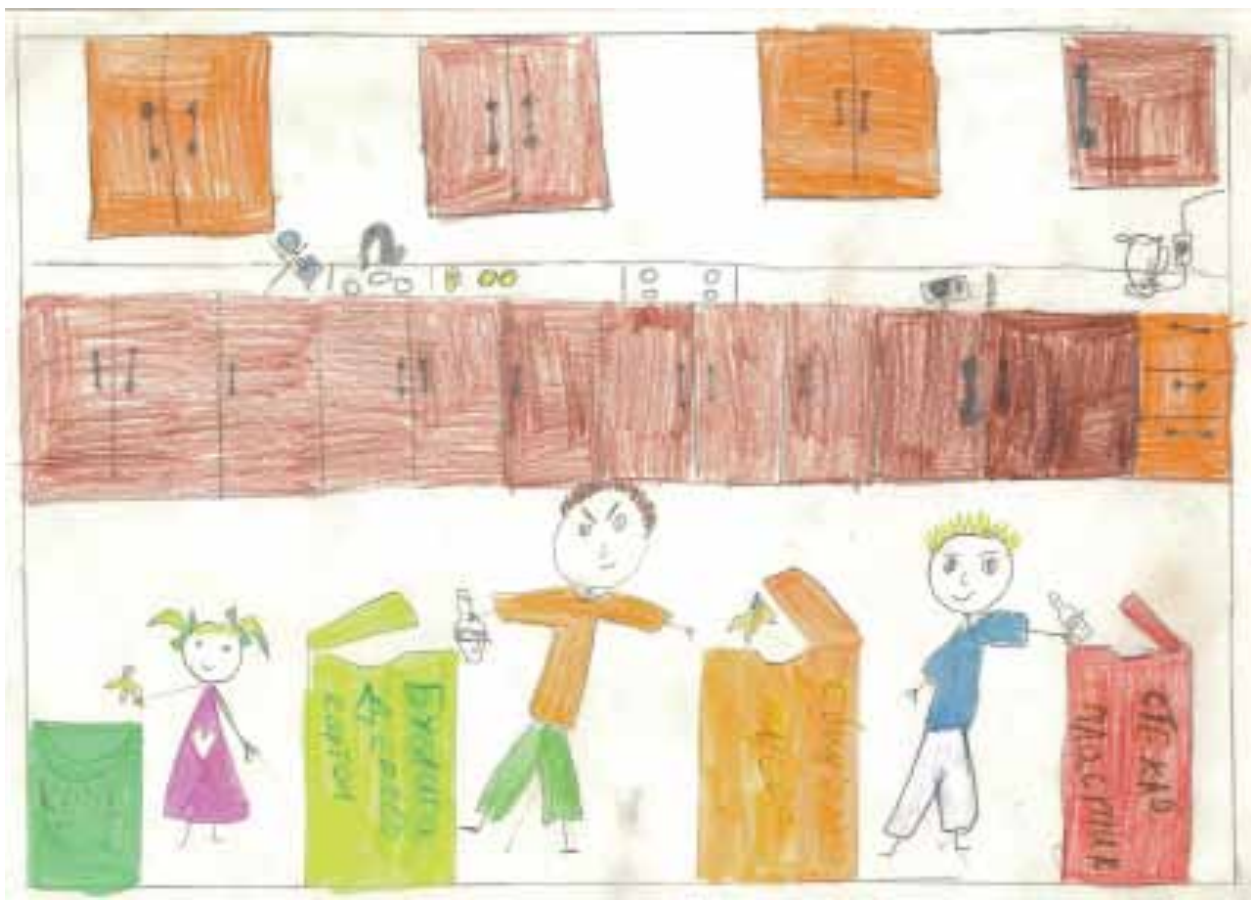

Kuva 11: Nastja Titova, 12 vuotta. 